\title{
De lo grave a lo grotesco en las cuevas cervantinas
}

\section{From the Grave to the Grotesque in Cervantes' Caves}

\author{
Ana Suárez Miramón \\ UNED \\ ESPAÑA \\ asuarez@flog.uned.es
}

[Hipogrifo, (issn: 2328-1308), 7.2, 2019, pp. 135-146]

Recibido: 30-05-2019 / Aceptado: 12-06-2019

DOI: http://dx.doi.org/10.13035/H.2019.07.02.13

Resumen. El motivo de la cueva en Cervantes tiene una gran importancia y está presente en todos los géneros, aunque es en la novela donde más se prodiga, constituyendo un elemento estructurante y narrativo. Hay obras, como el Persiles, cuya presencia está relacionada con el aspecto más grave como espacio mítico, pero en el Quijote, en cambio, puede verse una gradación simbólica entre el mito y la burla, como corresponde al sentido de la obra. Cervantes también utiliza el motivo para expresar la tragedia de los celos en la poesía, y en el teatro, y llega a la burla definitiva en el entremés.

Palabras clave. Cervantes; cueva; Persiles; Quijote.

Abstract. The motif of the cave in Cervantes is of great importance and is present in all genres, although it is in the novel where it is most commonly used constituting a structuring and narrative element. There are works, such as Persiles, where the cave is related to the most serious elements as a mythical space, but on the other hand, in Quixote, it is used as a symbolic gradation that can be interpreted as something in between myth and mockery, as it is seen in the meaning of the work. Cervantes also uses this motif to express the tragedy of jealousy in poetry, and in the theater, but even it reaches the highest level of mockery in the "entremés".

Keywords. Cervantes; cave; Persiles; Quixote.

En la obra cervantina se prodigan las cuevas, especialmente en el Quijote y en el Persiles, pero también en sus Novelas Ejemplares, y lo mismo en su teatro y poesía podemos encontrar cuevas de todo tipo, aunque ahora nos vamos a centrar en el 
tratamiento burlesco o incluso grotesco de las mismas para establecer la relación con las más serias. Es evidente que hay, junto a un tratamiento reflexivo, que recoge el carácter heroico de las cuevas como símbolos de iniciación o transformación, una deformación paródica de las mismas. A veces coinciden en un mismo espacio lo serio y lo grotesco, aunque lo más frecuente es que el autor proyecte una mirada doble, aunque no en el mismo lugar ni obra.

A diferencia del resto de sus escritos, en el Persiles no hay una mirada burlesca. Son espacios que recogen los símbolos tradicionales de las cuevas como lugares de salvación, de iniciación o regeneración y se extienden por la geografía europea, desde las islas del norte, y por ser territorios poco conocidos, o evocados, nunca tienen un nombre propio. La mayoría son cuevas naturales que aprovechan las personas para protegerse y otras han sido construidas para su salvación (física, religiosa o intelectual). Sin duda es la obra donde más cuevas serias aparecen y con significados más diferentes. Se encuentran en los espacios nórdicos y en Europa'. La primera coincide con el inicio de la novela, y constituye un auténtico vientre materno para los cautivos protagonistas, desde cuya estrecha boca, y tras las voces que daba el bárbaro Corsicurbo, sale a la luz Periandro (y la propia Auristela, aunque nos enteremos en un momento más adelantado del relato) y así comienzan el peregrinaje narrativo que descubre el lector en un principio.

La segunda cueva aparece en la isla bárbara. Es una cueva de salvación, primero para Antonio y después para él y su familia, por lo que funciona como un centro religioso, una especie de catacumba donde salvaguardar la vida y los principios católicos de Antonio inculcados a su familia bárbara. En el libro II, la nave volcada forma una cueva artificial que permite de nuevo la salvación de los peregrinos en una nueva tierra (la del rey Policarpo). En el Libro III, vuelve a aparecer otra cueva, ya muy diferente a las anteriores y, de alguna manera, recuerdo de la de Montesinos en el Quijote puesto que desde la oscuridad se llega a la luz. Se trata de la del español Soldino, adivino y astrólogo judiciario, afincado en suelo francés. Como en el episodio de la cueva de Montesinos, el narrador no se hace cargo directamente de la aventura (Cide Hamete la llega a considerar apócrifa) y en el Persiles se afirma: «el que escribió esta historia dice que»². El propio Soldino advierte a los peregrinos que la cueva no está encantada, sino que le sirve de atajo para llegar al valle ${ }^{3}$ que se puede contemplar a una legua de allí. Sin embargo, es también oscura, horadara en una ermita que el propio Soldino construyó, y por la que tuvieron que bajar casi «ochenta gradas» hasta acceder a «un cielo luciente y claro» donde encontraron unos amenos prados. Además de servirle de retiro físico y espiritual, Soldino había conseguido estudiar allí matemáticas y astrología, «sin libros», solo con la propia

1. Ya en pruebas de este trabajo, y una vez realizado un trabajo anterior presentado como ponencia al Congreso de la Asociación de Cervantistas (septiembre 2018), donde analizamos el aspecto serio de las cuevas del Persiles, hemos tenido conocimiento del estudio de Carles Magrinyá (2019), posterior a los nuestros, donde se pone de manifiesto la importancia de las cuevas como espacios fronterizos en la obra póstuma cervantina.

2. Cervantes, Persiles y Sigismunda, p. 601.

3. La mayoría de las cuevas que aparecen en el Sueño de Polífilo servían para llegar, igualmente, a un valle de luz, ameno y lleno de árboles. 
«experiencia de la soledad». Incluso les demuestra sus conocimientos al hacerles partícipes de lo que está viendo en ese momento («agora, agora, como presente, veo», nada menos que el fin de Alí Pachá con el triunfo de Lepanto y la muerte del joven don Sebastián de Portugal), y además Ilama a Croriano por su nombre sin que le conociese y pronostica a los peregrinos, además del fuego, su diferente final, como así ocurre en el relato. Esta cueva, a su vez enlaza en la narración con las profecías de Mauricio, también astrólogo, y con la de Montesinos del Quijote, puesto que, desde otra óptica, Soldino ve los acontecimientos de la historia española del mismo modo que don Quijote vio la realidad que se contaba en el romancero sobre sus admirados héroes. Sin embargo, en esta ocasión, Soldino, al haber acreditado cuanto decía, no deja dudas a los peregrinos sobre el valor de la astrología judiciaria. Su cueva reúne los elementos míticos, religiosos, iniciáticos, intelectuales y proféticos que simbolizan las cuevas desde la antigüedad, y esta representa una síntesis de las cuevas encantadas que don Quijote fue conociendo por libros o relatos y por su propia experiencia, onírica o real.

Si las cuevas del Persiles muestran una seriedad en su significado y en la estructura del relato, en el Quijote unas son literarias, pues proceden de las lecturas del protagonista; otras, ni siquiera tienen nombre y, sin embargo, las más importantes del relato sí lo tienen y se ubican en una realidad española conocida, una en el Campo de Montiel, la cueva de Montesinos, y otra, en el parque natural de la sierra subbética, la sima de Cabra. Esta última cueva, cuya peligrosidad era bien conocida en la época, llegó a convertirse en frase lexicalizada para expresar la heroicidad de una persona ante cualquier coyuntura, como si tradujera el máximo riesgo que implicaba para quien pudiera adentrarse. Con este sentido lexicalizado aparece en El celoso extremeño y en El viaje del Parnaso, como veremos.

Cervantes conocía perfectamente la tradición caballeresca y humanista donde se ofrecían múltiples ejemplos en los que los héroes encontraban en las cuevas la posibilidad de una gran aventura que les sirviera como prueba para manifestar que su amor por una dama no se detenía ante ninguna dificultad. Los ejemplos de El conde Partinuplés, Olivante de Laura, El caballero Cifar y el Amadís de Gaula así lo demuestran 4 . También conocía la literatura humanista, y la obra más importante, el Sueño de Polífilo ofrece grutas muy diversas a las que accede el protagonista como ejemplos de superación y pruebas obligadas para llegar a su amada Polia, aunque todo transcurra en un gran sueño. En el capítulo VI, por ejemplo, se interna en una muy oscura, que le recuerda a la clásica de Caco y la de Polifemo, pero de la que consigue salir a un espacio natural, ameno y lleno de luz. Este paso de la oscuridad a la luz, relacionado con el simbolismo platónico del nacimiento y regeneración o de descenso a los infiernos antes de llegar al cielo o a la verdad, propia de la literatura de visiones, se prodiga en la obra atribuida a Colonna ${ }^{5}$ que, por supuesto, es la culminación de una tradición que funciona como aventura y simbolismo platónico.

En el Quijote, antes de que aparezca la famosa de Montesinos en la Segunda parte, ya se prefigura, en el capítulo L de la Primera, en la historia fantástica del ca-

4. Rull, 1981.

5. Colonna, pp. 153-160. Ver para el tema Suárez Miramón, 2014 
ballero que se adentra en el lago ardiente, la semblanza del ideal de aventura de la cueva de Montesinos, como vio Rull6. Por su parte, Swansey destacó los elementos burlescos que vio también don Quijote en la famosa cueva? ${ }^{7}$. En el Quijote se pergeña muy pronto el descenso de su protagonista a la cueva de Montesinos como trasunto de la aventura ideal del caballero en la Primera parte. En la historia del lago, libresca, ya aparecen rasgos concretos que muestran una visión fantástica y grotesca a un tiempo y que adelantan elementos de la cueva más emblemática. El narrador insiste en la oscuridad total, en las aguas imposibles de atravesar y en la dificultad para esquivar las fieras que la ocupaban. Recordemos que de ese «gran lago de pez hirviendo a borbollones», lleno de «serpientes, culebras y lagartos y otros muchos géneros de animales feroces y espantables», procedía una voz tristísima que pedía ayuda ofreciéndole, a cambio de penetrar en su fondo, la posibilidad de contemplar «las altas maravillas que en sí encierra» y el caballero traspasó la oscuridad y llegó con su esfuerzo a «unos floridos campos superiores a los Elíseos»8. Esta idea de adentrarse en un espacio mágico, lago o cueva, le andaba rondando a nuestro héroe por las mientes desde muy temprano porque se correspondía con las historias que había leído y en ellas se ofrecía todo un mundo de belleza tras atravesar la oscuridad primera.

Pero para que esta idea se fijase aún más en su mente, en el capítulo XIV de la Segunda parte, otro Caballero, el disfrazado Sansón Carrasco, bajo el nombre de Caballero del Bosque, le contó a don Quijote los trabajos que él tuvo que sufrir por «la sin par Casildea de Vandalia», siempre con la esperanza, que nunca vio cumplida, de obtener su amor. La cueva a la que se refería este Caballero era muy conocida en la época, la sima de Cabra. Aunque la invención de Sansón Carrasco debía funcionar como un freno para don Quijote y que pudiera olvidar su empresa, lo cierto es que obró el efecto contrario y le animó aún más a llevar a cabo una empresa como la del supuesto caballero. El Caballero del Bosque, enamorado de «la sin par Casildea de Vandalia», fue obligado a realizar trabajos sobrehumanos; ella le pidió luchar contra la Giralda, llevar a cuestas los Toros de Guisando y, lo peor, que se adentrara en la sima de Cabra, mítico paraje al que no se acercaba nadie por su extraordinaria profundidad y el peligro que entrañaba:

Otra vez me mandó que me precipitase y sumiese en la sima de Cabra, peligro inaudito y temeroso y que le trujese particular relación de lo que en aquella escura profundidad se encierra. Detuve el movimiento a la Giralda, pesé los Toros de Guisando, despeñéme en la sima y saqué a luz lo escondido de su abismo, y mis esperanzas, muertas que muertas, y sus mandamientos y desdenes, vivos que vivos ${ }^{9}$.

No se nos cuenta cómo sobrevivió, aunque entre las leyendas en torno a este lugar se conocía la de un caballero cordobés, Sebastián de Alcudia, quien al ver en los alrededores de la sima ropas femeninas, bajó y rescató a una dama noble cuya

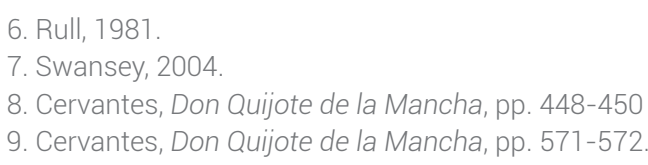


familia la había arrojado por desobedecer los designios de la misma de aceptar un casamiento pactado y, aunque consiguió subir con ella, ni Sebastián de Alcudia ni Sansón Carrasco contaron lo que vieron en ese abismo egabrense, tan peligroso y profundo que los pastores del lugar lo consideraban una de las bocas del infierno.

Cervantes no se limitó a utilizar la sima como hipérbole de lo que sucedió a este Caballero, sino que utilizó el lugar legendario para expresar que más allá de aquella sima no podía existir nada más peligroso. Por ello, cuando en El celoso extremeño, cuya casa parece también una auténtica cueva por ser un espacio cerrado, lóbrego y oscuro, las criadas de Leonora hacen jurar a Loaysa que no hará más que lo que ellas le ordenaran, y jura por el monte Líbano, por Carlomagno y Fierabrás, una de las doncellas dio grandes voces diciendo. "- ¡Este sí que es juramento para enternecer las piedras! ¡Mal haya yo si más quiero que jures, pues con solo lo jurado podías entrar en la misma sima de Cabra!» ${ }^{10}$. El alcance del juramento del joven amante sirvió como una especie de conjuro heroico que le capacitaba incluso para penetrar en la histórica cueva y, desde luego, sus palabras equivalían a un acta notarial.

Definitivamente, tras los ejemplos de la laguna ardiente y la sima de Cabra, don Quijote decide adentrarse en la de Montesinos para experimentar por sí mismo el misterio de sus profundidades y salir, a la vez, airoso de la prueba para encontrar a su amada. Esta cueva representa, por una parte, una inflexión seria en el devenir de don Quijote, pero también apunta al carácter grotesco de ciertos elementos allí presentes que la emparienta con la profunda de Cabra. Hay una cierta coincidencia en su profundidad, de «doce o catorce estados» la de Cabra, mientras que casi cien brazas de soga utilizaron para el descenso del caballero en la de Montesinos, por lo que a ambas se las denomina sima; en la de Montesinos se concreta su forma, una «concavidad», cuya dificultad consagraba a la «sin par Dulcinea». Sin embargo, a diferencia del caballero del Bosque, don Quijote, en sueños o despierto, sí vio lo que guardaba su interior. Lo primero que descubrió fue un luminoso prado, y tras él, un suntuoso alcázar por una de cuyas puertas salía un venerable anciano, grotescamente vestido. Así se le presentó Montesinos. Ya Swansey señaló el vestuario ridículo y los movimientos que tienen los personajes en esta cueva, en donde aquel, Belerma y sus doncellas aparecen ataviados de manera incongruente ${ }^{11}$. Pero, además, en esa visión se consideraba a Merlín culpable de todas las desgracias de los héroes. Este famoso sabio encantador, que sabía más que el diablo, se muestra relacionado con otras cuevas cervantinas como La casa de los celos, cuyo espíritu se hace presente.

Por si fuera poco, en el transcurso de la novela se van sucediendo episodios grotescos que guardan una estrecha correspondencia con el descenso de la cueva de Montesinos y apuntalan la diversidad de visiones propias de Cervantes. En la Segunda parte del Ingenioso Hidalgo (capítulo LIV) tiene lugar, primero, el episodio burlesco del duelo fingido de Tosilos, estrechamente ligado a la caída de Sancho a una cueva, que la anticipa. Los duques habían dispuesto el desafío de Tosilos con nuestro hidalgo (fingido naturalmente, aunque don Quijote lo ignora), pero ya que el

10. Cervantes, El celoso extremeño, p. 50

11. Swansey, pp. 393-394. 
mozo burlador de la moza en cuestión no estaba presente, pues se hallaba huido en Flandes, según se nos dice, por no querer tener de suegra a doña Rodríguez: «ordenaron poner en su lugar a un lacayo gascón que se llamaba Tosilos»12. Tras esta burla, en el capítulo siguiente (el 50), a Sancho, que se había entretenido en el camino con Ricote, se le hizo de noche y en esa noche «algo escura y cerrada», cayeron él y su rucio, a una honda cueva, una «escurísima sima», pensando «que no había de parar hasta el profundo de los abismos», pero no fue así porque la tal "sima" tenía una profundidad de «poco más de tres estados», aunque quedaron maltrechos ambos y sin poder salir. El propio Sancho establece entonces el paralelo entre este suceso y la aventura de la cueva de Montesinos que aconteció a su amo:

A lo menos no seré yo tan venturoso como lo fue mi señor don Quijote de la Mancha cuando descendió y bajó a la cueva de aquel encantado Montesinos, donde halló quien le regalase mejor que en su casa ${ }^{13}$.

Cervantes repite la aventura del caballero, pero ahora dentro de los límites de la más prosaica realidad contrahaciendo la historia heroica y fantástica del amo y repitiéndola en clave de farsa en el criado. Y no es aventura ideada por la crítica, sino que, como ya se ha indicado, es el propio Sancho quien la refiere.

Este episodio grotesco y triste para Sancho ya estaba anticipado en la burla de la aventura de Tosilos, y resulta una especie de parodia del descenso de don Quijote a la de Montesinos. A Sancho le sacan de su caída, con lo que concluye, en cierto modo simbólico, la burla de los duques al darle el gobierno de la ínsula, ya que incluso su triunfo en la batalla, en la que por cierto quedó como un cobarde, fue también fingido. Bodas y caídas (de Basilio y Tosilos, y de don Quijote y Sancho respectivamente) se establecen en una correspondencia indudable. Unos relatos son precedentes de otros, en una secuencia perfectamente calculada por el autor entre antecedentes y consecuentes pues las bodas fingidas de Tosilos no son sino una parodia de las Bodas de Camacho. Por tanto, el episodio de la caída de Sancho y la boda de Tosilos aparecen en un tono grotesco y carente del menor idealismo frente a los modelos anteriores de las bodas de Basilio y la bajada de don Quijote a la cueva de Montesinos. Sin embargo, en las dos bodas se trata de escenificar un engaño y una burla. Basilio utilizaba la palabra industria, mientras que la dama burlada por el galán y los duques, y de paso por el aprovechado Tosilos, empleaba el término reiterado de engaño, y algo parecido ocurre en las cuevas. Si la caída de Sancho es un contrapunto burlesco de la cueva de Montesinos, admitido así por el propio escudero, también la sima de Cabra, de la que el Caballero del Bosque, en un engaño para forzar a volver a la cordura a don Quijote, sacó «lo escondido de su abismo», en la de Montesinos también dio a conocer lo «escondido» de su interior y, entre toda la galería de personajes que contempló, la imagen de Dulcinea se grabó en su mente, no ya como la de su enamorada, sino como la desengañada visión que percibió el del Bosque de su «Casildea de Vandalia», pues a partir de entonces don Quijote no vuelve a ser el mismo ni tampoco su Dulcinea. Parecen resonar

12. Cervantes, Don Quijote de la Mancha, p. 834.

13. Cervantes, Don Quijote de la Mancha, pp. 841-842. 
en él las palabras del disfrazado personaje al bajar a su cueva («mis esperanzas, muertas que muertas y sus mandamientos y desdenes, vivos que vivos») y, aunque no lo acepte directamente, la duda sobre el engaño de su ideal resulta otro eslabón que se va adaptando a la evolución del protagonista y al nuevo ritmo que toma la novela desde entonces.

De esta manera, Cervantes recrea sus propios episodios dentro de una obra tan compleja para contrastarlos, variarlos y alterarlos, de forma que en cada caso los caracteriza con unos matices y sentido muy diferentes, precedidos además de contextos que prefiguran ese tono y ese valor distintos. Los episodios "nobles" de la cueva de Montesinos, frente a la cueva de Sancho, anuncian claramente que estamos ante realidades diametralmente opuestas, y lo mismo ocurre con la sima de Cabra respecto a la de Montesinos y la aparente "sima" donde cayó Sancho. Cervantes utiliza episodios similares, en unos casos en clave digamos "heroica", mientras en otro en clave de farsa, y de esta manera hace germinar una historia nacida de otra, precedida de contextos similares y anunciadores, hasta conseguir una recreación constante de sus propios episodios y técnicas narrativas. Sin embargo, como en un racimo personajes, lugares y detalles son utilizados con intenciones muy diferentes ${ }^{14}$.

Si de la sima de Cabra nunca pudo contar el caballero del Bosque lo que vio, dejando así en suspense a su vecino, sí percibió el desengaño que encontró y Cervantes utilizó el peligro de esa cueva para burlarse de los malos poetas. En el apartado dedicado a los «Privilegios, ordenanzas y advertencias que Apolo envía a los poetas españoles» y que cierra la Adjunta al Parnaso, se refiere a modo de premática burlesca al terror que infundían en la época los malos poetas, y cuyas consecuencias podían llegar hasta el propio suicidio en la citada sima por desesperación de los lectores. Dice así la advertencia:

Ítem, se da por aviso particular que si alguna madre tuviere hijos pequeñuelos traviesos y llorones, los pueda amenazar y espantar con el coco, diciéndoles: «Guardaos, niños, que viene el poeta fulano, que os echará con sus malos versos en la sima de Cabra» ${ }^{15}$.

No hay que olvidar que, a diferencia de estas cuevas concretas, Cervantes ubicó también en cuevas la morada de los celos y por tanto las consecuencias funestas del amor. Un ejemplo es el romance de 1600 titulado «La morada de los celos» y otro, la singular comedia La casa de los celos. En el romance se describe así la cueva de los celos:

Yace donde el sol se pone, entre dos tajadas peñas, una entrada de un abismo, quiero decir, una cueva,

14. Sobre este episodio de Tosilos ya Enrique Rull hizo unas observaciones que relacionaban las cuevas de Montesinos y Sancho, la una en clave seria y la otra como parodia.

15. Cervantes, El viaje del Parnaso, p. 173. 
profunda, lóbrega, obscura,

aquí mojada, allí seca,

propio albergue de la noche,

del horror y las tinieblas.

Ese espacio, también, como la laguna y la cueva de Montesinos, está habitada por nefastos animales que impiden el paso:

Por las funestas paredes,

por los resquicios y quiebras,

mil víboras se descubren

y ponzoñosas culebras.

La «morada de celos y sospechas» que había contemplado un pastor no le extrañó a Lauso porque él mismo conocía «un vivo traslado» de esa cueva en su pecho, debido a los celos por Silena («los celos son los que habitan / en esta morada estrecha»)

Convertida la cueva en metáfora de los celos, aún aparece en otra ocasión, en la comedia La casa de los celos, muy próxima al romance en la descripción de los celos (II jornada), y aquí se presenta en espíritu el propio Merlín, a quien don Quijote vio en el interior de la cueva de Montesinos, que ahora se queja de permanecer en la selva oscura ${ }^{16}$. El legendario profeta y encantador, compañero del rey Arturo, merece también un afectuoso recuerdo por parte de Pedro de Urdemalas, por su gran sabiduría, y el otro personaje, Malgesí, que en esta misma obra era recordado por ser quien predijo su futuro, se considera en La casa de los celos el portero de esa cueva. Se describe a sí mismo de este modo:
portero de aquesta puerta,
Soy el Horror,
adonde vive el temor
y la sospecha más cierta
que engendra el cielo de amor.
Soy ministro de los duelos,
embajador de los celos,
que habitan en esta cueva ${ }^{17}$.

Reinaldos, al descubrir una boca espantosa entre la maleza, dentro de los variados espacios de la obra ${ }^{18}$, se había lanzado a la misma buscando también una aventura, pero se había encontrado con la cueva de los celos, con las mismas características negativas que las simas anteriores, aunque aquí las llamas sustituyen al peligro de las fieras:

De entre estas hojas entiendo que sale el horrible estruendo.

16. Cervantes, La casa de los celos, p. 164.

17. Cervantes, La casa de los celos, p. 194.

18. Ver el estudio y la bibliografía que aporta al tema González, 2014. 
Mas, jay!, ¿qué boca espantosa,

terrible y estraña cosa,

es aquesta que voy viendo?

Mientras más vomitas llamas,

boca horrenda o cueva oscura,

más me incitas y me inflamas.

Además de establecer nuevas relaciones entre las cuevas narrativas, las poéticas y las teatrales, estas de los celos, relacionadas con el amor, representan de alguna manera la dramatización del infierno de los enamorados y adelantan la posibilidad de nuevas secuencias, como las burlas de los entremeses donde los maridos son engañados precisamente porque han construido, para evitar que sus mujeres más jóvenes puedan tener relaciones con amantes, vecinas o familiares, auténticas cuevas, bien guardadas y vigiladas, aunque al fin las encerradas logren escapar a la luz. Es lo que ocurre, de manera grotesca, en el entremés de La cueva de Salamanca.

Al igual que la cueva de Cabra, aunque por razones distintas, la de Salamanca era también muy famosa, en este caso entre los estudiantes, que se divertían en el siglo XVI con conjuros, hechizos y prácticas diabólicas. La leyenda contaba que la cueva estaba en una cripta perteneciente a la ya desaparecida iglesia de San Cebrián, y allí el Demonio daba clases de ciencias ocultas (magia, adivinación y astrología) y recibía a siete alumnos cada siete años. Tras ese tiempo, uno de ellos era obligado a quedarse dentro y se cuenta que solo el marqués de Villena logró escapar, aunque se quedó sin sombra.

A esta cueva se refiere Cervantes en el entremés, y su burla, aunque en apariencia solo es al marido de Leonarda, Pancracio, en realidad implica un vuelco grotesco del resto de las cuevas cervantinas. En principio, la trama es muy sencilla. Pancracio tiene que ausentarse de su casa por unos días y mientras él se va, su mujer, Leonarda, y su doncella Cristina, han quedado con un sacristán y un barbero para cenar los ricos y variados manjares preparados por ellos. Cuando todo está dispuesto, un nuevo personaje irrumpe en la acción. Es un estudiante, que busca acomodo para pasar la noche. Enseguida aparece el marido que, debido a una rotura del carruaje, regresa de su viaje al poco de haberlo iniciado. Para sacar a todos del aprieto, el estudiante Carraolano se hace pasar por nigromante después de confesar a Pancracio haber pasado por la cueva de Salamanca. El crédulo Pancracio, que ya había mostrado su interés por los poderes mágicos (aunque solo fuese al utilizar unas palabras al oído de su esposa para calmarla de su aparente disgusto por quedarse sola), se cree todo cuanto va viendo en ese teatro de la ilusión con el que todos se burlan. La confesión del estudiante le permite utilizar un conjuro del que para nada sospecha el incauto Pancracio. Le dice así:

La ciencia que aprendí en la Cueva de Salamanca, de donde yo soy natural, si se dejara usar sin miedo de la Santa Inquisición, yo sé que cenara y recenara a 
costa de mis herederos; y aun quizá no estoy muy fuera de usalla..., pero no sé yo si estas señoras serán tan secretas como yo lo he sido ${ }^{19}$.

Curiosamente, la cueva de Salamanca resulta el contrapunto caricaturesco de la cueva de Soldino (Persiles). Si para aquel anciano su cueva «era un sustento para las alma», la de Salamanca es, evidentemente el sustento para los cuerpos, y Pancracio se entusiasma con la oportunidad que le brinda el estudiante; solo quiere ver los efectos de esa magia ("ya deseo en todo extremo ver algunas destas cosas que dice se aprenden en la cueva de Salamanca» ${ }^{20}$ ) y, por supuesto, ve cómo «los demonios» van sacando la comida. Sin embargo, ahora la cueva no es tal, sino la oscura y humilde carbonera de la casa de Pancracio. El estudiante realiza su conjuro a los diablos («vosotros, que en la carbonera / hallastes amparo a vuestra desgracia / salid, y en los hombros, con priesa y con gracia, / sacad la canasta de la fiambrera») y él mismo entra en la improvisada cueva para hacerlos salir más deprisa. Todos participan en la fiesta, que termina con canciones en las que se burlan de la cueva de Salamanca y con el deseo de Pancracio de aprender esas ciencias de Salamanca.

Aunque la parodia es total, como corresponde a un entremés, empezando por convertir la mítica cueva en una humilde y popular carbonera, resultan interesantes los comentarios sobre el temor a la justicia, el miedo a las figuras (propias de la magia negra), a la Inquisición y, sin embargo, el interés por ver a los diablos, en un nuevo ejemplo de la sugestión de Cervantes por las cuevas, la magia y los hechizos, aunque nunca traspasen el límite de la doble ficción.

A partir de esta diversidad de cuevas, donde pueden encontrarse desde lo heroico y caballeresco, a lo mítico y lo legendario, lo sagrado y lo profano, el amor y sus enemigos, los celos, las prácticas de encantamiento y adivinación, el entremés La cueva de Salamanca parece extraer diferentes elementos de toda la diversidad de cuevas para mostrar la imagen grotesca de todo lo que el ideal caballeresco, de salvación y de principios éticos y conocimientos había mantenido en la obra más seria.

En gran medida, en el motivo de las cuevas se puede descubrir la compleja visión, seria, dramática y burlesca, tan presente siempre en Cervantes. Si en el Quijote la variedad del motivo se deriva de la propia urdimbre de la novela y enlaza con todo el contexto mítico y, en el otro extremo, el entremés utiliza la cueva para expresar el tema del «engaño de maridos», presente en otras obras cervantinas, lo cierto es que el ámbito cerrado de ciertas casas, donde está la mujer aislada y en la oscuridad, se puede identificar con la legendaria cueva de los celos. El tema del engaño surge precisamente de esa cueva, pero, en lugar de terminar con la vida del amante que sospecha, es la vida la que se libera de las fuerzas ocultas.

Todas las cuevas cervantinas guardan relación con los reductos mágicos, nobles o no, de los libros caballerescos, ámbitos que podríamos llamar "sagrados", en tanto que no pertenecen al mundo natural, sino al de una ficción mítica o mágica, y 
por tanto a un mundo sobrenatural, y esto lo mismo vale para un texto falsamente épico como el del Quijote como para uno grotesco y degradado como el del entremés, o para uno melancólico y nostálgico como el del Persiles. Aunque en La cueva de Salamanca Cervantes consigue la mejor burla de las cuevas, después de haber reunido las más variadas en toda su obra y de haber jugado con ellas para transmitir, en serio o en burla, un sentimiento que debe salir al exterior (vida, libertad, ilusiones deseadas, principios éticos), lo cierto es, que en esa gradación desde la cueva seria a la grotesca, se encuentra una de las cualidades de la escritura cervantina, la de hilvanar temas y motivos muy diversos a partir de un mismo símbolo al que va dotando de diferentes significados.

\section{BiBLIOGRAFÍA}

Cervantes, Miguel de, Don Quijote de la Mancha, ed. Alberto Blecua y Andrés Pozo, Madrid, Espasa Calpe, 1998.

Cervantes, Miguel de, La casa de los celos y selvas de Ardenia, en El gallardo español y La casa de los celos, ed. Antonio Rey Hazas y Florencio Sevilla, Madrid, Alianza, 1997, pp. 141-248.

Cervantes, Miguel de, La cueva de Salamanca, en Entremeses, ed. Florencio Sevilla y Antonio Rey Hazas, Madrid, Alianza Editorial, 1998, pp. 151-170.

Cervantes, Miguel de, El celoso extremeño, ed. Florencio Sevilla y Antonio Rey Hazas, Madrid, Alianza Editorial, 1997.

Cervantes, Miguel de, Persiles y Sigismunda, ed. Carlos Romero, Madrid, Cátedra, 2002.

Cervantes, Miguel de, Poesías sueltas, en Obras completas, II, Madrid, Aguilar, 2003, pp. 1057-1080.

Colonna, Francesco, Sueño de Polífilo, ed. y traducción Pilar Pedraza, Madrid, El Acantilado, 1999.

González, Aurelio, «La casa de los celos y selvas de Ardenia y la propuesta cervantina de la multiplicidad espacial», en Actas selectas del VII Congreso Internacional de la Asociación de Cervantistas, Oviedo (17-15 de junio de 2012), coord. Emilio Martínez Mata y María Fernández Ferreiro, Oviedo, Fundación María Cristina Masaveu Peterson, 2014, pp. 963-976.

Magrinyá, Carles, «Función y significación de la cueva en Los trabajos de Persiles y Sigismunda, historia setentrional», Hipogrifo, 7.1, 2019, pp. 187-200.

Rull, Enrique, «El arquetipo del caballero encantado en el Quijote a través de los topoi de la laguna y el palacio encantados», Anales cervantinos, 19, 1981, pp. 57-67. 
Suárez Miramón, Ana, «Cervantes y el Sueño de Polífilo», en Actas selectas del VII Congreso Internacional de la Asociación de Cervantistas, Oviedo (1 1-15 de junio de 2012), coord. Emilio Martínez Mata y María Fernández Ferreiro, Oviedo, Fundación María Cristina Masaveu Peterson, 2014, pp. 255-265.

Swansey, Bruce, «La cueva especular: de Montesinos a Zaratustra», en Cervantes y su mundo, vol. 1, Kassel, Edition Reichenberger, 2004, pp. 383-406. 